\title{
On the Performance of Sentinel3 Altimetry Over New Reservoirs: Approaches to Determine Onboard A Priori Elevation
}

Zhang, Xingxing; Jiang, Liguang; Kittel, Cecile M. M.; Yao, Zhijun; Nielsen, Karina; Liu, Zhaofei; Wang, Rui; Liu, Jun; Andersen, Ole B.; BauerGottwein, Peter

\section{Published in:}

Geophysical Research Letters

Link to article, DOI:

10.1029/2020GL088770

Publication date:

2020

Document Version

Publisher's PDF, also known as Version of record

Link back to DTU Orbit

Citation (APA):

Zhang, X., Jiang, L., Kittel, C. M. M., Yao, Z., Nielsen, K., Liu, Z., Wang, R., Liu, J., Andersen, O. B., \& Bauer Gottwein, P. (2020). On the Performance of Sentinel3 Altimetry Over New Reservoirs: Approaches to Determine Onboard A Priori Elevation. Geophysical Research Letters, 47(17), [e2020GL088770].

https://doi.org/10.1029/2020GL088770

\section{General rights}

Copyright and moral rights for the publications made accessible in the public portal are retained by the authors and/or other copyright owners and it is a condition of accessing publications that users recognise and abide by the legal requirements associated with these rights.

- Users may download and print one copy of any publication from the public portal for the purpose of private study or research.

- You may not further distribute the material or use it for any profit-making activity or commercial gain

- You may freely distribute the URL identifying the publication in the public portal 


\section{Geophysical Research Letters}

\author{
RESEARCH LETTER \\ 10.1029/2020GL088770 \\ Key Points: \\ - The Sentinel-3A altimeter cannot \\ deliver useful data over many \\ reservoirs (constructed after 2005) in \\ open-loop tracking mode with \\ OLTC V5 \\ - Defining correct a priori elevation \\ information is the key to increasing \\ data availability over reservoirs \\ - Four approaches are proposed to \\ define the most accurate onboard a \\ priori elevation
}

Supporting Information:

- Supporting Information S1

- Table S1

Correspondence to:

L. Jiang,

ljia@env.dtu.dk

Citation:

Zhang, X., Jiang, L., Kittel, C. M. M., Yao, Z., Nielsen, K., Liu, Z., et al. (2020) On the performance of Sentinel-3 altimetry over new reservoirs:

Approaches to determine onboard a priori elevation. Geophysical Research Letters, 47, e2020GL088770. https://doi. org/10.1029/2020GL088770

Received 11 MAY 2020

Accepted 7 AUG 2020

Accepted article online 17 AUG 2020

\section{On the Performance of Sentinel-3 Altimetry Over New Reservoirs: Approaches to Determine Onboard A Priori Elevation}

\author{
Xingxing Zhang ${ }^{1,2,3}$ (D) Liguang Jiang ${ }^{2}$ (D), Cécile M. M. Kittel ${ }^{2}$ (D), Zhijun Yao' ${ }^{1}$ Karina Nielsen ${ }^{4}$, \\ Zhaofei Liu' ${ }^{1}$, Rui Wang ${ }^{1}$ (D) Jun Liu ${ }^{2}$, Ole B. Andersen ${ }^{4}$ (D), and Peter Bauer-Gottwein ${ }^{2}$ (iD \\ ${ }^{1}$ Key Lab for Resources Use and Environmental Remediation, Institute of Geographic Sciences and Natural Resources \\ Research, Chinese Academy of Sciences, Beijing, China, ${ }^{2}$ Department of Environmental Engineering, Technical \\ University of Denmark, Kongens Lyngby, Denmark, ${ }^{3}$ College of Resources and Environment, University of Chinese \\ Academy of Sciences, Beijing, China, ${ }^{4}$ DTU Space, National Space Institute, Technical University of Denmark, Kongens \\ Lyngby, Denmark
}

\begin{abstract}
Satellite radar altimetry has become an important data source supplementing in situ water level. For practical reasons, a radar altimeter can only record reflected echoes within its range window. Therefore, water surface elevation must fall within the range window. To this end, the Sentinel-3 radar altimetry mission is configured with a new tracking function (i.e., open loop) to position its range window based on an onboard a priori elevation of ground targets. We found that Sentinel-3 is unable to observe recently built reservoirs due to the incorrect onboard elevations. To overcome this issue, four approaches are proposed to improve the a priori elevation for inland water bodies, particularly reservoirs. These approaches can significantly increase data availability of Sentinel-3 over reservoirs and can be used to prepare the onboard elevations of reservoirs and lakes for future missions such as Sentinel-6, Sentinel-3C/-3D, and the Surface Water and Ocean Topography (SWOT) mission.
\end{abstract}

Plain Language Summary Satellite radar altimetry is increasingly being used for hydrological studies. However, it is still challenging to deliver high-quality data over inland water bodies, that is, lakes, rivers, and reservoirs. One of the reasons is that the altimeter cannot easily identify the water surface elevation due to highly variable terrain elevation along the satellite flight path. In other words, the data delivered may not contain valid information for water bodies. To address this issue, Sentinel-3 is configured with a new function, which informs the altimeter about the expected elevation of the water surface.

However, this function demands a priori knowledge of the altitude of the ground targets. We present four approaches to improve the a priori information to increase data availability over inland water bodies, specifically reservoirs.

\section{Introduction}

Dams and reservoirs play an important role in social and economic development. Reservoirs are used to generate hydroelectric power, to mitigate floods, and to secure water supplies for human consumption, industrial use, irrigation, and so forth (Nilsson, 2009; Wang et al., 2017; Zarfl et al., 2014; Zhou et al., 2016). Tens of thousands of reservoirs have been built in the past century, and many new reservoirs are still under construction or being planned (Lehner et al., 2011). However, in many cases, reservoir construction requires the relocation of local communities due to the inundation of land. Moreover, reservoir construction and management significantly change flow regimes. Concerns have been raised about the negative impact of reservoir construction on the environment and local communities, especially in the downstream areas, given the background of climate change and population growth (Richter et al., 2010; Zarfl et al., 2014; Zhou et al., 2016). Therefore, reservoir monitoring and management is becoming more critical, particularly for transboundary river basins (Crétaux et al., 2015). Reservoir water surface elevation (WSE) is an essential variable because it directly tracks reservoir storage and thus water availability downstream of the reservoir. The most newly built dams have been equipped with sophisticated in situ monitoring systems to obtain long-term and consistent records. Unfortunately, these data sets are not publicly available partially due to geopolitical concerns (Hannah et al., 2011; Schneider et al., 2017; Thu \& Wehn, 2016). Research assessing
(C)2020. American Geophysical Union. All Rights Reserved. 

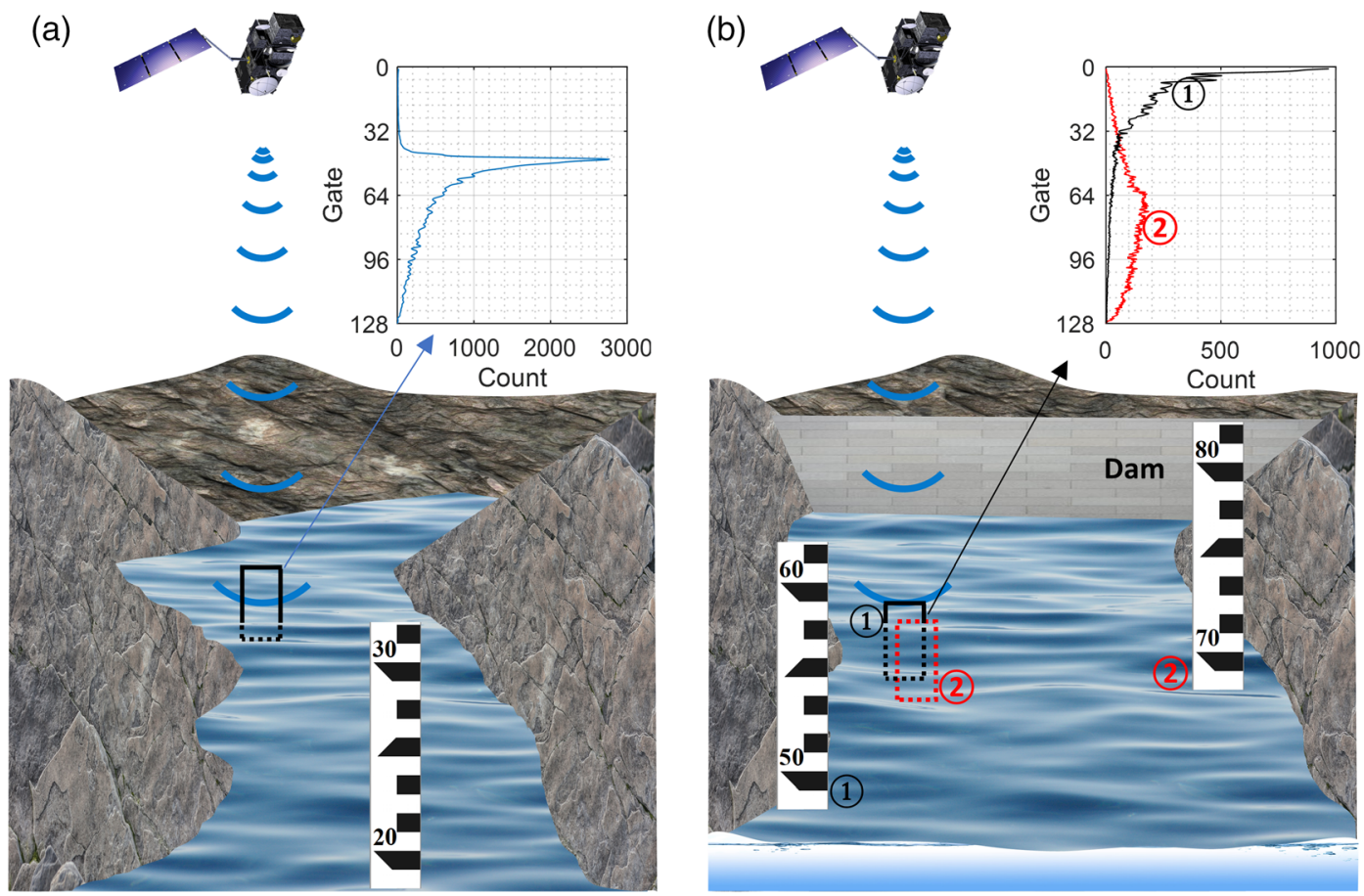

Figure 1. Schematic presentation of the range window position problem. (a) Onboard a priori elevation correctly represents the ground truth before dam construction. In this case, the range window (solid line indicates portion above, dotted line the portion below the water surface) is positioned correctly. Therefore, the altimeter is able to record reflected echoes from water, and a full waveform (upper-right plot, spanning $60 \mathrm{~m}$ ) is acquired. (b) After dam construction, onboard a priori elevation does not represent ground truth anymore. Therefore, the range window is positioned too low (too late in time) to record echoes returned from water surface. Depending on the rise of WSE after dam construction, the recorded signals could be the trailing edge of the waveform (Scenario (1): a small portion (solid black line) of the window is above the water surface) or just background noise (Scenario (2): the full window (dotted red line) is below the water surface).

the role and impact of dams and reservoirs on society and the environment has so far been limited due to a lack of data, particularly at transboundary and global scales (Mulligan et al., 2020). It is therefore crucial to apply alternative and efficient techniques to collect comprehensive regional-scale reservoir WSE data sets and make them publicly available.

Satellite radar altimetry has been increasingly used to study inland water bodies such as rivers, lakes, and reservoirs on regional to global scales since the 1990s (Asadzadeh Jarihani et al., 2013; Biancamaria et al., 2017; Birkett, 1995; Crétaux \& Birkett, 2006; Frappart et al., 2006; Jiang et al., 2017b; Jiang, Madsen, \& Bauer-Gottwein, 2019; Jiang, Schneider, et al., 2017). The precision of satellite altimetry derived WSE has improved significantly when compared to the first satellite altimeter developed three decades ago (Jiang et al., 2020; Koblinsky et al., 1993; Nielsen et al., 2017). Nowadays, altimetry data, acquired by both conventional LRM (low-resolution mode) altimeters (e.g., Envisat, Jason-2/-3, and SARAL/AltiKa) and SAR (synthetic aperture radar) altimeters, have been broadly explored to study regional water resources (e.g., Crétaux et al., 2016; Jiang et al., 2017a; Papa et al., 2015), lake dynamics (e.g., Baup et al., 2014; Jiang et al., 2017a; Kraemer et al., 2020), hydrologic modeling (e.g., Hulsman et al., 2020; Kittel et al., 2018; Michailovsky et al., 2013; Pereira-Cardenal et al., 2011), and parameterization of river models (e.g., Domeneghetti et al., 2014; Jiang, Madsen, \& Bauer-Gottwein, 2019; Schneider et al., 2018). However, none of the altimetry missions are specifically designed for inland water monitoring. It is still challenging to deliver high-quality data over inland water bodies. Partially because altimeters have problems tracking water surfaces of lakes, rivers, and reservoirs, particularly those surrounded by rugged topography (Biancamaria et al., 2018; Desjonquères et al., 2010; Jiang et al., 2020; Martin-Puig et al., 2016). To acquire as much data as possible, different onboard tracking methods have been proposed and tested, such as the Envisat Model Free Tracker, the Jason-1 Split-gate tracker, the Jason-2 Diode/Median tracker, and the Diode/DEM 
tracker (Desjonquères et al., 2010; Gommenginger et al., 2011; Martin-Puig et al., 2016). The Diode/DEM mode (i.e., open-loop mode) was first tested onboard Jason-2 and SARAL/AltiKa missions (Desjonquères et al., 2010; Steunou et al., 2015). Currently, it is used as the operational mode for Jason-3 and Sentinel-3. The open-loop tracking system can position the range window very efficiently based on a priori elevation stored onboard. Therefore, it is important to inform the tracking system with the most accurate a priori elevation information.

Sentinel-3 is configured with a new onboard tracking system, that is, the open-loop tracking function. In principle, this feature can increase data availability over both coastal regions and inland water bodies. However, the static nature of the onboard elevation may result in some practical challenges. Specifically, Sentinel-3A (S3A) is operating based on a pseudo-DEM controlled through the Open-Loop Tracking Command (OLTC) (Le Gac et al., 2019). The OLTC is being periodically updated. The current OLTC onboard Sentinel-3A (operated since March 2019) is Version 5 (V5), which includes 33,000 hydrology targets (Blumstein et al., 2019). The OLTC V5 was generated mainly based on inland water masks (the Global Inundation Extent from Multi-Satellites [GIEMS], the Shuttle Radar Topography Mission [SRTM] Water Body Data [SWBD], and the Global Surface Water Explorer [GSW]), the global SRTM DEM and the Hydroweb database (http://hydroweb.theia-land.fr/). The SRTM DEM was measured during an 11-day mission in February of 2000. Hence, the a priori elevation for many reservoirs built after 2005 is most likely incorrect. As illustrated in Figure 1, the altimeter cannot record a complete signal of the water surface anymore since the construction of dams. The altimetry data could be just noise if the WSE of the reservoir rises by more than $30 \mathrm{~m}$ (assuming that the a priori elevation is in the middle of the range window). In this study, our hypothesis is that the onboard elevations for newly built large reservoirs are wrong, and thus, altimetry data are invalid.

The objective of this study is to examine data availability and the validity of S3A over recently constructed large reservoirs. We investigate waveforms and Level-2 WSE to understand the reason for data unavailability and invalidity. To address this problem, we propose four approaches to improve the a priori elevation. We expect that the approaches will improve the performance of Sentinel-3 altimeters (Sentinel-3A/-3B) as well as other upcoming satellite altimetry missions (Sentinel-6 and Sentinel-3C/-3D) for inland water monitoring.

\section{Materials and Methods}

\subsection{Reservoir and Dam Database}

The global reservoir and dam database (GRanD) provides a single, geographically explicit, and reliable source of information on reservoirs and dams (Lehner et al., 2011). The latest version, GRanD v1.3, includes a total of 7,320 reservoirs globally (storage capacity $>0.1 \mathrm{~km}^{3}$ ), of which 347 were constructed after 2005 . A comprehensive attribute table assembled from numerous sources is available, including the height of the dam, the average depth of the reservoir, and the year in which the dam was built (Lehner et al., 2011). Considering the potential problems with Sentinel-3 data acquisition described in the previous section, we select the reservoirs for this study based on the following criteria:

1. Reservoirs intersected by S3A ground tracks;

2. Reservoirs built after 2005; and

3. Reservoirs with a dam height higher than $100 \mathrm{~m}$.

In this way, 62 globally distributed reservoirs are selected. In addition, another nine reservoirs across different continents are randomly selected to examine the validity of S3A data over these relatively smaller reservoirs. Figure 2 shows the spatial distribution of the selected reservoirs and the coverage of the open-loop mode before March 2019.

\subsection{Sentinel-3A Data and Processing}

S3A altimetry products are downloaded from the Copernicus Open Access Hub (https://scihub.copernicus. eu/dhus/\#/home). The enhanced measurement data file used in this study contains Level-1b waveforms and associated parameters as well as the Level-2 standard $20 \mathrm{~Hz}$ parameters. Note that before March 2019, S3A operated in both open loop and closed loop for different regions, as indicated in Figure 2. After 9 March 2019, all areas within $60^{\circ} \mathrm{N}$ to $60^{\circ} \mathrm{S}$ are covered in open-loop mode. Thirty-seven reservoirs were located in the 


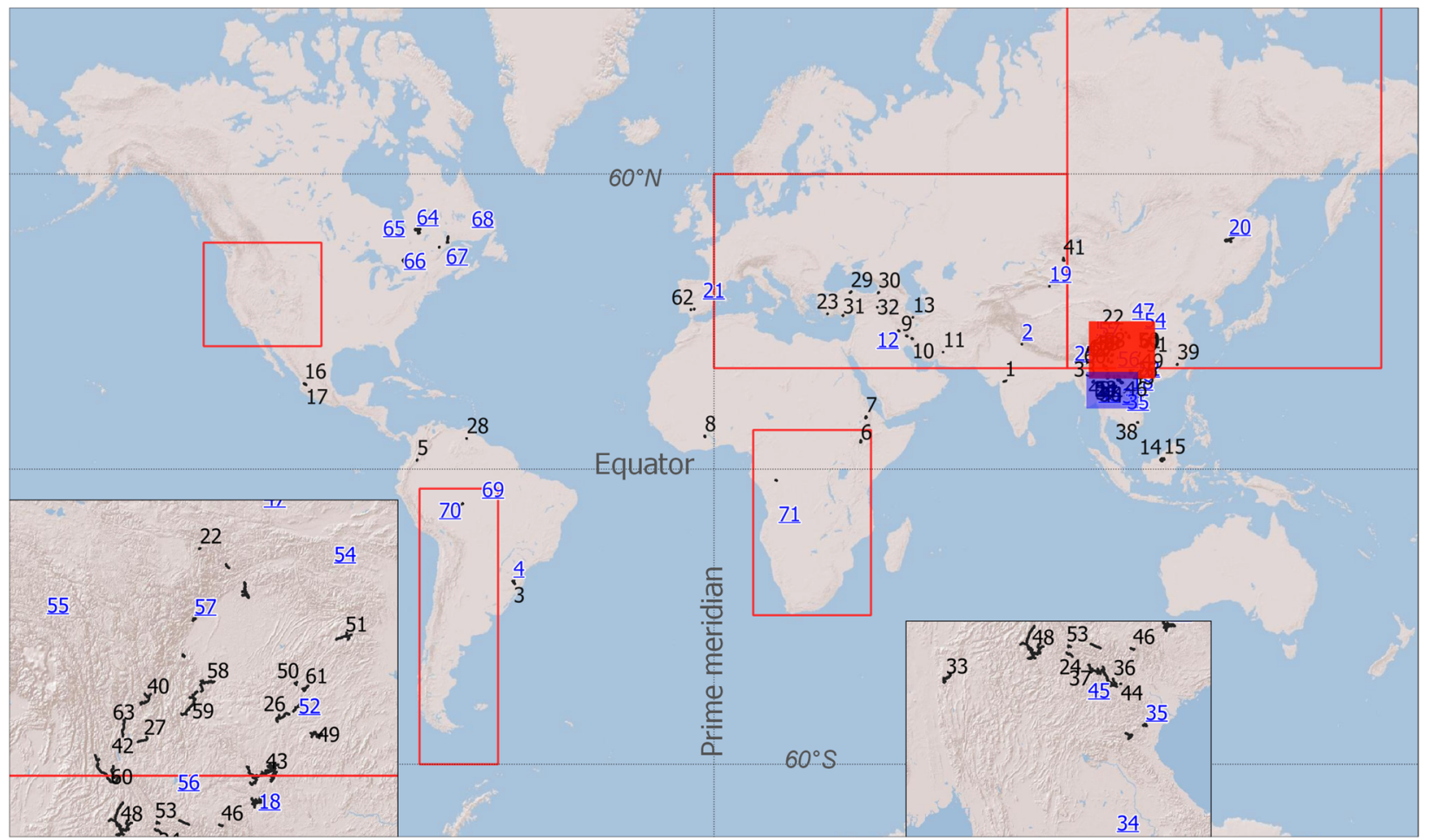

Figure 2. Locations of studied reservoirs. The left-bottom and right-bottom insets are zoomed views of the red and blue shaded rectangles, respectively. Regions where S3A operated in open loop before March 2019 are indicated by red boxes, including 37 reservoirs. Other regions were covered in closed loop. After 9 March 2019 , all areas within $60^{\circ} \mathrm{N}$ to $60^{\circ} \mathrm{S}$ are covered in open loop. Labels in blue indicate reservoirs with good performance.

regions covered in open loop, while 34 were in regions covered in closed-loop mode. For predefined open-loop regions before March 2019, a limited number of targets (mostly in France) were defined with an appropriate a priori elevation. More details about the onboard elevation definition can be found in previous publications (e.g., Jiang et al., 2020; Le Gac et al., 2019) and on the OLTC website (https://www.altimetry-hydro.eu/). Data of both periods are used to explore the behavior of the S3A tracker in different modes.

For the first step to select potential measurements of reservoir WSE, the water occurrence map (occurrence $>10 \%$ ) of the Global Surface Water Explorer (Pekel et al., 2016) is used. A low threshold of $10 \%$ is chosen for two reasons: (1) Water occurrences are expected to be low for new reservoirs and (2) a lower threshold ensures that a higher number of potential measurements are preselected.

To assess whether the range window is positioned reasonably, we investigated waveforms along each pass. The waveform shape (i.e., the presence of the leading edge if it exists) and the maximum power are good indicators of data validity and quality (Jiang et al., 2020; Le Gac et al., 2019). Specifically, we first construct a new waveform by taking the gate-wise median value of all waveforms over a reservoir. The rationale is the assumption that all these waveforms contain one common peak that corresponds to the reservoir water surface, even though individual waveforms may be contaminated by other bright targets (Jiang et al., 2020). Note that waveforms were first adjusted by the automatic gain control (AGC) values (available in the product) to make them comparable. Second, based on the maximum power (40,000 counts, based on our statistics) and the corresponding gate position (between 4 and 125) of the constructed waveform, we assess the data validity of each pass. Here, we assume that the leading edge occupies two to three gates. If the maximum power occurs between Gates 4 and 125, we treat this peak as the leading edge, thereby classifying the waveform as valid. The corresponding pass is classified as successful in terms of range window positioning. In the end, a success rate is calculated for each reservoir based on the number of valid passes and total passes in the period. If the data are missing for a given pass, this pass is also classified as invalid. 
The actual range window position can be inferred from the tracker range (available in the data set), which is the distance between the antenna and nominal tracker point. Applying all associated corrections, the elevation of the nominal tracker point can be obtained and compared with DEMs, for example, the up-to-date TanDEM-X DEM (https://tandemx-science.dlr.de/). In principle, if the range window does not contain the water surface of the reservoirs, then the water surface echo is not recorded in the waveforms. Thus, the delivered data is invalid, and in most cases, the signal power is relatively low.

To retrieve the WSE of a reservoir, potential measurements selected from the first step are further processed. Here the first outlier removal procedure is based on the backscatter coefficient $\left(\sigma^{0}\right)$. A backscatter coefficient $\left(\sigma^{0}\right)$ threshold of $30 \mathrm{~dB}$ is used to remove obvious outliers (Kittel et al., 2020). Note that $\sigma^{0}$ and the orthometric WSE are estimated using the OCOG retracker. Furthermore, outliers within each pass are removed using the median of absolute deviation (Jiang, Andersen, et al., 2019). The remaining data points are used to construct time series using tsHydro (Nielsen et al., 2015).

\subsection{Approaches to Define the A Priori Elevation for New Reservoirs}

Four approaches are proposed and summarized in Table S1 in the supporting information. Here, we discuss these methods in detail. The most appropriate a priori elevation of inland water bodies can be obtained from satellite altimetry. Although the closed-loop mode is not ideal, the altimeter can deliver quite a lot of valid data in closed loop if the topography does not change too abruptly. Therefore, the first approach is to make use of the S3A data collected in closed loop (with the exception of areas tracked in open-loop mode; refer to Figure 2) during the first approximately 3 years (before March 2019). The second approach uses other satellite altimetry missions to derive WSE time series. CryoSat-2 and AltiKa (drifting phase) data are used here because of their dense ground tracks. Similar data processing procedures are used as for S3A. Once the time series is available, the optimal range window position can be determined.

However, not all studied reservoirs are successfully sampled by CryoSat- 2 or AltiKa. In these cases, we propose to estimate WSE based on the dam heights available from the GRanD database. The top of the range window can be set at the same elevation as the crest of the dam. The rationale behind this approach is that the normal water level (an optimum highest reservoir WSE) is usually lower than the dam height by a few meters (Sun et al., 2011). Recall that only the height of dam is available; therefore, in order to obtain the elevation of the crest, dam base elevation is approximated using the ACE2 DEM, which represents the ground elevation before dam construction.

The fourth approach is based on the TanDEM-X DEM, which is currently the most recent, accurate, and publicly available global DEM (Wessel et al., 2018). This global DEM is based on data collected between December 2010 and January 2015, representing the latest global terrain heights. The lowest point along the satellite ground tracks crossing each reservoir is chosen to represent the reservoir water level.

\section{Results and Discussion}

\subsection{Performance}

The majority of the studied reservoirs are located in Asia and the Eastern Mediterranean Region (Figure 2). Figure 3 demonstrates the waveforms and range window positions corresponding to four scenarios that we observed in the S3A data set for the entire period. The power of a waveform generally indicates whether the reflected echoes are valid. As shown in Figures $3 b$ and 3c, valid signals are much stronger than the invalid ones, which are essentially background noise. This is corroborated by the range window position. The range window (the green area in Figure 3d) is positioned too high before March 2019 or, in other words, too early to record the signals bounced back from the water surface. The current elevation is appropriate, and the range window encompasses the water surface. Note that both passes were in open loop in this example, and therefore, an appropriate a priori elevation is vital to acquire valid signals.

Unfortunately, the current open-loop configuration does not deliver useful data over most of the studied reservoirs. As demonstrated in the second row of Figure 3, the range window is positioned too low to capture the waveform peaks (Figure 3g). On the other hand, the closed loop successfully captured the water surface (Figure 3f). However, the closed loop is not robust, and data are sometimes invalid or completely unavailable due to the loss of tracking. In this particular case, the reason for the wrong window position in open loop is 

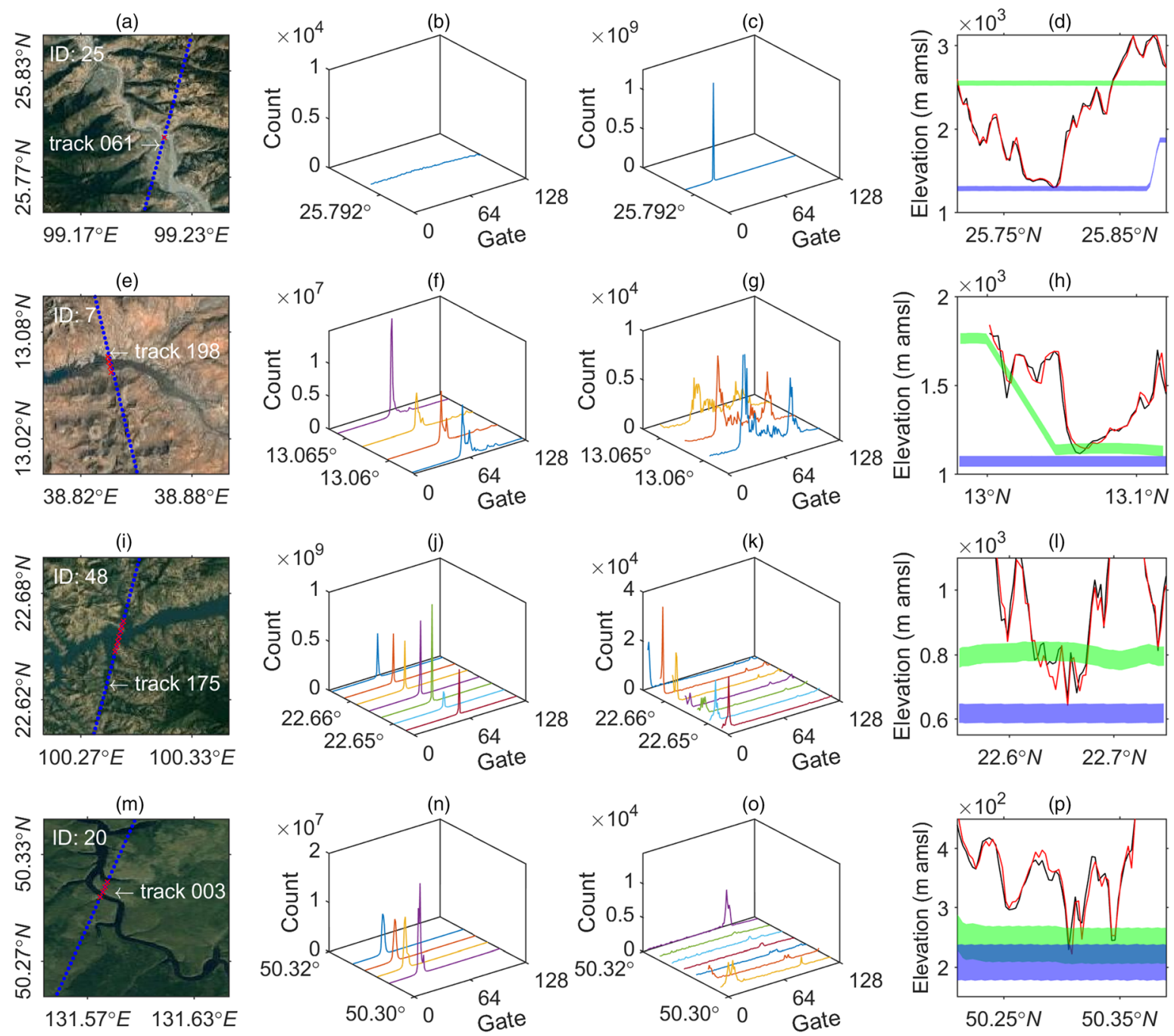

Figure 3. Selected Level-1b waveforms and Level-2 measurements to illustrate four different scenarios. The first column (a, e, i, and $\mathrm{m}$ ) indicates the location of the reservoir of each scenario. The second column (b, f, j, and n) shows waveform in either closed loop or open loop before the update of onboard elevation. The third column (c, g, k, and o) shows waveform acquired in open loop with current new a priori elevation. The last column (d, h, l, and p) shows the range window position before and after the update of a priori elevation (shaded area; green and blue correspond to waveforms shown in columns 2 and 3 , respectively) and DEM (solid line; ACE2 in black and Tandem-X in red) of corresponding ground track. The first row (a-d) shows that S3A failed to deliver valid data in previous open loop, while it works well in current open loop. The second row (e-h) shows that S3A can occasionally detect reservoir in closed loop but fails to deliver valid data without a priori onboard elevation. The third row (i-1) demonstrates that valid data were acquired when S3A operated in closed loop, while invalid data are delivered in open loop. The last row $(\mathrm{m}-\mathrm{p})$ shows the scenario that valid data are available in previous open-loop mode, but no valid data are available in current open-loop mode. Abbreviation: amsl stands for above mean sea level.

that the a priori elevation for this reservoir is not defined. The onboard tracker simply uses the elevation of the previous target along the ground track.

The position of the leading edge of the waveform can indicate whether the range window is well positioned. The third row of Figure 3 exemplifies cases where the leading edge reveals a poorly positioned range window. At the shown target, the altimeter detects the water surface in closed-loop mode (Figure 3j) but fails in open-loop mode as revealed by the waveform. Clearly, the leading edge is missed due to the low position of the range window. The range window aligns well with the ground topography as indicated by the two DEMs. However, the elevation data set is outdated due to the sharp rise of water level after dam construction. In this case, only the trailing edge of echoes is within the range window. Similarly, Figures $3 m-3 p$ show a problem with the current elevation. Although no a priori elevation is defined for this reservoir prior to March 2019, the altimeter worked well using the elevation of the previous target and useful data were 


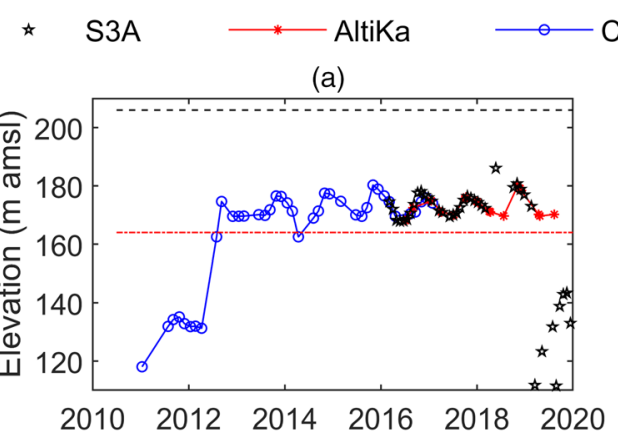

CrySat-2

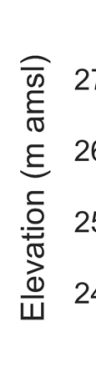

(b) $\mathrm{H}_{\text {Dam crest }}$

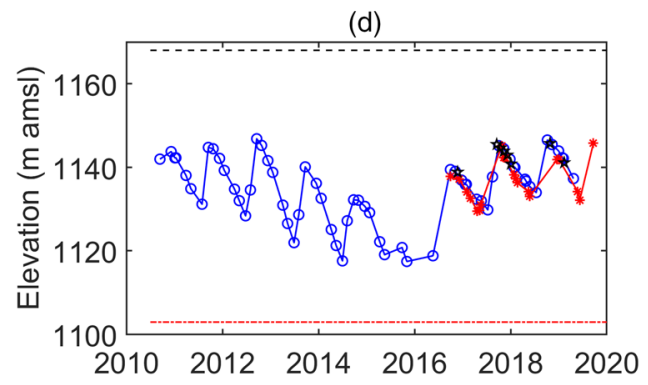

Figure 4. Comparison of a priori elevation derived from altimetry derived time series, TanDEM-X, and dam height for four representative reservoirs behind dams (a-d) Bui (Ghana), Bureya (Russia), Garzan (Turkey), and Tekeze (Ethiopia), corresponding to 8, 20, 32, and 7 as indicated in Figure 2.

delivered. However, the update introduced faulty elevation, and the reservoir is no longer correctly monitored.

Based on the success rate of data acquisition, the performance statistics of S3A are summarized in Table S2. As expected, S3A did not deliver consistent valid data over the majority of the reservoirs. The success rate is above $50 \%$ only at 25 reservoirs (see the blue ID in Figure 2). Except for the 14 reservoirs without an a priori elevation, most of the current elevations are too low. This is especially true for reservoirs with a very high dam. Here, the range window is badly positioned and results in a low probability to capture the signals reflected from water surface. Due to large seasonal fluctuations of the water level, a fixed elevation cannot guarantee a $100 \%$ success rate of data acquisition. This partially explains the lower success rates of the majority reservoirs (Table S2). Comparatively, the closed-loop mode does not perform much worse; 28 of 34 reservoirs have at least $10 \%$ of valid data. However, only $30 \%$ reservoirs have more than $80 \%$ of valid data. This corroborates the lack of robustness of the closed-loop mode. Nevertheless, the closed-loop outperforms the open loop in terms of success rates (see the first two columns in Table S2). This suggests that the closed loop may be a good choice if a priori information is unavailable or unreliable.

\subsection{Determination of A Priori Elevation}

Based on altimetry measurements, Sentinel-3, CryoSat-2, and AltiKa provide a result for 47, 53, and 44 reservoirs, respectively (see Table S3 and time series in Figure S4). They show very good agreements with correlation values of nearly one, although biases exist between different altimeters. Unlike Sentinel-3, CryoSat-2 and AltiKa in long-repeat (geodetic) orbits have much denser ground tracks, and thus monitoring more hydrology targets. These data sets (likely high resolution due to the SAR/SARIn mode or Ka band) also show a high potential of preparing elevation for other missions, such as Sentinel-6.

As presented in Figure 4, the time series can clearly show the maximum water level as well as the dynamics of the water levels. The WSE derived from CryoSat-2, AltiKa, and S3A are in excellent agreement. In spite of the rugged topography, CryoSat-2 captured the sharp rise of the WSE due to the construction of dams (Figures 4a and 4c) as well as the drawdown (Figure 4d) in 2016 due to extreme drought. These examples also highlight the value of altimetry for reservoir monitoring. However, CryoSat-2 has difficulty observing WSE when the reservoir is close to empty. In the example illustrated by Figure $4 \mathrm{~b}$, both S3A and AltiKa 
observed the low WSE while CryoSat-2 did not. We found that the CryoSat-2 observations of this reservoir are very noisy during these low-level periods.

In general, this approach allows us to properly define an a priori elevation with consideration of water level dynamics. This is extremely important when the amplitude of the seasonal variation is significant (see examples in Figure S3). Seasonal WSE changes might be of the same order as the range window size, that is, $60 \mathrm{~m}$. That is, a static range window position may not be appropriate at all times, missing either peaks or troughs. Therefore, the determination of an a priori elevation could prioritize the high-level condition to monitor flood risk. Furthermore, under low-level conditions, the water surface extent of reservoirs becomes narrower; thus, it is difficult to obtain useful data.

However, for some reservoirs, there is not an available valid time series of the WSE. In this case, we have to rely on the information of the dam height and the global DEM. As shown in Figure 4, the approach based on the dam height is always applicable. If the top of the range window is set to the elevation of the dam crest, the WSE at the high-level condition can be guaranteed, but the WSE at the low-level may be missed if the seasonal variation is more than $60 \mathrm{~m}$. A compromise is therefore needed. The results provided by this approach generally agree with the other approaches (Table S3). However, if a reservoir is still filling up and has not yet reached the desired operating level, the estimate based on the dam crest elevation will overestimate actual WSE. Moreover, the accuracy is also affected by the accuracy of the global DEM given that the elevation of the dam base is derived from DEM.

Comparatively, an a priori elevation derived from a global DEM is less accurate mainly because of the static nature of a DEM data set. As shown in Figure 4, the a priori elevation derived from the TanDEM-X is inappropriate. Even if the TanDEM-X elevation is used as the end of the range window, the WSE in high-level condition cannot be guaranteed. It is worth noting that the conditions under which the DEM data were collected (i.e., high level, low level, or in between) are unknown. Without this information, it is difficult to set the range window. Among the four investigated approaches, the results provided by the DEM-based approach are the worst. For only 16 reservoirs, the actual WSE falls within $30 \mathrm{~m}$ of the estimated WSE (Table S3). This also indicates that current OLTC V5 contains unreasonable elevations based on global SRTM DEM. For some more shallow reservoirs, the approach works well, but those are exceptions. Recall that nine reservoirs with dam height smaller than $100 \mathrm{~m}$ (69 m in reality) are also selected. The OLTC V5 values of these reservoirs are mostly appropriate and are generally in agreement with results provided in this study (Table S3).

Apparently, a priori elevation defined based on the altimetry-derived WSE is the most accurate. It is worth noting that the first two approaches probably do not work well over small reservoirs, for which altimetry measurements are usually of low quality. In this regard, the ICESat-2 laser altimeter, which has much higher resolution and precision, can be very helpful to obtain the WSE dynamics after 2 years of operation.

Beyond the approaches discussed here, operations in closed-loop mode in the commissioning phase or during the first year of a mission could be an option instead of operating in open loop without proper elevation. Another possibility is to make use of the data in the end-of-life phase. This geodetic phase will significantly increase the coverage of hydrology targets. However, the occurrence of tracking loss cannot be avoided in closed-loop mode. Last, but not least, frequent updates of the onboard a priori elevation are also a good strategy to avoid delivering too much invalid data over the course of the mission lifetime.

\section{Summary and Conclusions}

To maximize the value of altimeters over inland water bodies, an open-loop tracking mode is adopted on Sentinel-3A/-3B. A determinant of the data acquisition in open-loop mode over inland water bodies is the a priori onboard elevation. The definition of a priori elevation for global inland water bodies is challenging, especially for newly built reservoirs. We assessed the suitability of the current onboard a priori elevation data for 71 globally distributed reservoirs, mostly built after 2005 .

By investigating waveforms and Level-2 heights, we found that the onboard a priori elevation is appropriate for a minor portion (35\%) of the studied reservoirs. In most cases, the elevation is too low due to the sharp increase of the water level after the dam construction. Moreover, for 14 reservoirs, no a priori elevation is defined, probably because the reservoirs are not defined in water masks, which are used to define the 
targets. Moreover, we found that closed-loop tracking mode delivered useful data for some reservoirs but did not perform consistently. In summary, the value of Sentinel-3A over these reservoirs is degraded due to the inappropriate a priori elevation. To address this problem, we used four approaches to define/improve the a priori information of the onboard elevation.

It is obvious that the determination of an a priori elevation from the earlier and successful Sentinel-3A, CryoSat-2, and AltiKa acquisitions is the most appropriate solution, because the full dynamics of the reservoir water level is available and the range window can then be positioned to exactly match user needs. However, due to the limitation of the closed-loop mode over rugged topography, reliable altimetry observations are not available for all reservoirs. Thus, we suggest that closed loop should still be preferred over open loop if no a priori information is available. A few cycles in closed loop at the very beginning of a new mission might be a reasonable compromise. The second approach based on dam height information from a global database is also effective. Given that the WSE cannot be higher than the dam elevation, the range window can be positioned to ensure that high-level conditions can be observed. In cases where no dam height is available, we propose to use the TanDEM-X DEM elevations as an alternative source of information. A global DEM represents a transient state of the reservoir water levels; therefore, if this method is used, the most appropriate approach may be to reference the middle point of the range window to the TanDEM-X elevation.

In conclusion, the methods presented in this study can help define and improve the a priori elevation. By ensuring that the elevation is correct and up to date, the data availability over reservoirs, as well as other inland water bodies, can potentially be greatly increased. Our suggested approaches are also applicable to other altimeters that are, or will be, operating in the open-loop mode, such as Jason-3 and future Sentinel-6 and Sentinel-3C/-3D.

\section{Data Availability Statement}

Data sets used in this study are all publicly available. GRanD database is available at http://globaldamwatch. org/data/\#core_global (accessed 11 May 2020). Sentinel-3 data are publicly accessible at https://scihub. copernicus.eu/dhus/ (accessed 11 May 2020). AltiKa data are downloaded from AVISO+ at https://www. aviso.altimetry.fr/data.html (accessed 11 May 2020). CryoSat-2 is available at https://science-pds.cryosat. esa.int/ (accessed 11 May 2020). TanDEM-X DEM is accessible at https://geoservice.dlr.de/web/dataguide/tdm90/ (accessed 11 May 2020). ACE2 DEM is available at https://sedac.ciesin.columbia.edu/data/ set/dedc-ace-v2 (accessed 11 May 2020). SRTM DEM is downloaded from USGS at https://earthexplorer. usgs.gov/ (accessed 19 June 2020).

\section{References}

Asadzadeh Jarihani, A., Callow, J. N., Johansen, K., \& Gouweleeuw, B. (2013). Evaluation of multiple satellite altimetry data for studying inland water bodies and river floods. Journal of Hydrology, 505, 78-90. https://doi.org/10.1016/j.jhydrol.2013.09.010

Baup, F., Frappart, F., \& Maubant, J. (2014). Combining high-resolution satellite images and altimetry to estimate the volume of small lakes. Hydrology and Earth System Sciences, 18(5), 2007-2020. https://doi.org/10.5194/hess-18-2007-2014

Biancamaria, S., Frappart, F., Leleu, A.-S., Marieu, V., Blumstein, D., Desjonquères, J.-D., et al. (2017). Satellite radar altimetry water elevations performance over a 200 m wide river: Evaluation over the Garonne River. Advances in Space Research, 59, 128-146. https:// doi.org/10.1016/j.asr.2016.10.008

Biancamaria, S., Schaedele, T., Blumstein, D., Frappart, F., Boy, F., Desjonquères, J. D., et al. (2018). Validation of Jason-3 tracking modes over French rivers. Remote Sensing of Environment, 209, 77-89. https://doi.org/10.1016/j.rse.2018.02.037

Birkett, C. M. (1995). The contribution of TOPEX/POSEIDON to the global monitoring of climatically sensitive lakes. Journal of Geophysical Research, 100(C12), 25,179-25,204. https://doi.org/10.1029/95JC02125

Blumstein, D., Lasson, L., Le Gac, S., Biancamaria, S., Calmant, S., Crétaux, J. F., et al. (2019). Major upgrade of OLTC on Sentinel-3A and 3B in 2018: Benefits for inland waters users. In Living planet symposium.

Crétaux, J., Biancamaria, S., Arsen, A., Bergé-nguyen, M., \& Becker, M. (2015). Global surveys of reservoirs and lakes from satellites and regional application to the Syrdarya river basin. Environmental Research Letters, 10, 15002. https://doi.org/10.1088/1748-9326/10/1/ 015002

Crétaux, J.-F., Abarca-del-Río, R., Bergé-Nguyen, M., Arsen, A., Drolon, V., Clos, G., \& Maisongrande, P. (2016). Lake volume monitoring from space. Surveys in Geophysics, 37(2), 269-305. https://doi.org/10.1007/s10712-016-9362-6

Crétaux, J. F., \& Birkett, C. (2006). Lake studies from satellite radar altimetry. Comptes Rendus Geoscience, 338(14-15), 1098-1112. https:// doi.org/10.1016/j.crte.2006.08.002

Desjonquères, J. D., Carayon, G., Steunou, N., \& Lambin, J. (2010). Poseidon-3 radar altimeter: New modes and in-flight performances. Marine Geodesy, 33(S1), 53-79. https://doi.org/10.1080/01490419.2010.488970

Domeneghetti, A., Tarpanelli, A., Brocca, L., Barbetta, S., Moramarco, T., Castellarin, A., \& Brath, A. (2014). The use of remote sensing-derived water surface data for hydraulic model calibration. Remote Sensing of Environment, 149, 130-141. https://doi.org/ 10.1016/j.rse.2014.04.007 
Frappart, F., Calmant, S., Cauhopé, M., Seyler, F., \& Cazenave, A. (2006). Preliminary results of ENVISAT RA-2-derived water levels validation over the Amazon basin. Remote Sensing of Environment, 100(2), 252-264. https://doi.org/10.1016/j.rse.2005.10.027

Gommenginger, C., Thibaut, P., Fenoglio-Marc, L., Quartly, G., Deng, X., Gómez-Enri, J., et al. (2011). Retracking altimeter waveforms near the coasts. In Coastal altimetry (pp. 61-101). Berlin, Heidelberg: Springer Berlin Heidelberg. https://doi.org/10.1007/978-3-64212796-0_4

Hannah, D. M., Demuth, S., van Lanen, H. A. J., Looser, U., Prudhomme, C., Rees, G., et al. (2011). Large-scale river flow archives: Importance, current status and future needs. Hydrological Processes, 25(7), 1191-1200. https://doi.org/10.1002/hyp.7794

Hulsman, P., Winsemius, H. C., Michailovsky, C. I., Savenije, H. H. G., \& Hrachowitz, M. (2020). Using altimetry observations combined with GRACE to select parameter sets of a hydrological model in a data-scarce region. Hydrology and Earth System Sciences, 24(6), 3331-3359. https://doi.org/10.5194/hess-24-3331-2020

Jiang, L., Andersen, O. B., Nielsen, K., Zhang, G., \& Bauer-Gottwein, P. (2019). Influence of local geoid variation on water surface elevation estimates derived from multi-mission altimetry for Lake Namco. Remote Sensing of Environment, 221, 65-79. https://doi.org/10.1016/j. rse.2018.11.004

Jiang, L., Madsen, H., \& Bauer-Gottwein, P. (2019). Simultaneous calibration of multiple hydrodynamic model parameters using satellite altimetry observations of water surface elevation in the Songhua River. Remote Sensing of Environment, 225, 229-247. https://doi.org/ 10.1016/j.rse.2019.03.014

Jiang, L., Nielsen, K., Andersen, O. B., \& Bauer-Gottwein, P. (2017a). CryoSat-2 radar altimetry for monitoring freshwater resources of China. Remote Sensing of Environment, 200, 125-139. https://doi.org/10.1016/j.rse.2017.08.015

Jiang, L., Nielsen, K., Andersen, O. B., \& Bauer-Gottwein, P. (2017b). Monitoring recent lake level variations on the Tibetan Plateau using CryoSat-2 SARIn mode data. Journal of Hydrology, 544, 109-124. https://doi.org/10.1016/j.jhydrol.2016.11.024

Jiang, L., Nielsen, K., Dinardo, S., Andersen, O. B., \& Bauer-Gottwein, P. (2020). Evaluation of Sentinel-3 SRAL SAR altimetry over Chinese rivers. Remote Sensing of Environment, 237, 111546. https://doi.org/10.1016/j.rse.2019.111546

Jiang, L., Schneider, R., Andersen, O. B., \& Bauer-Gottwein, P. (2017). CryoSat-2 altimetry applications over rivers and lakes. Watermark, 9(3), 211. https://doi.org/10.3390/w9030211

Kittel, C., Jiang, L., Tøttrup, C., \& Bauer-Gottwein, P. (2020). Sentinel-3 radar altimetry for river monitoring-A catchment-scale evaluation of satellite water surface elevation from Sentinel-3A and Sentinel-3B. Hydrology and Earth System Sciences Discussions, 1-35. https://doi.org/10.5194/hess-2020-165

Kittel, C. M. M., Nielsen, K., Tøttrup, C., \& Bauer-Gottwein, P. (2018). Informing a hydrological model of the Ogooué with multi-mission remote sensing data. Hydrology and Earth System Sciences, 22(2), 1453-1472. https://doi.org/10.5194/hess-22-1453-2018

Koblinsky, C. J., Clarke, R. T., Brenner, A. C., \& Frey, H. (1993). Measurement of river level variations with satellite altimetry. Water Resources Research, 29(6), 1839-1848. https://doi.org/10.1029/93WR00542

Kraemer, B. M., Seimon, A., Adrian, R., \& McIntyre, P. B. (2020). Worldwide lake level trends and responses to background climate variation. Hydrology and Earth System Sciences, 24(5), 2593-2608. https://doi.org/10.5194/hess-24-2593-2020

Le Gac, S., Boy, F., Blumstein, D., Lasson, L., \& Picot, N. (2019). Benefits of the Open-Loop Tracking Command (OLTC): Extending conventional nadir altimetry to inland waters monitoring. Advances in Space Research. https://doi.org/10.1016/j.asr.2019.10.031

Lehner, B., Liermann, C. R., Revenga, C., Vörösmarty, C., Fekete, B., Crouzet, P., et al. (2011). High-resolution mapping of the world's reservoirs and dams for sustainable river-flow management. Frontiers in Ecology and the Environment, 9(9), 494-502. https://doi.org/ $10.1890 / 100125$

Martin-Puig, C., Leuliette, E., Lillibridge, J., \& Roca, M. (2016). Evaluating the performance of Jason-2 open-loop and closed-loop tracker modes. Journal of Atmospheric and Oceanic Technology, 33(11), 2277-2288. https://doi.org/10.1175/JTECH-D-16-0011.1

Michailovsky, C. I., Milzow, C., \& Bauer-Gottwein, P. (2013). Assimilation of radar altimetry to a routing model of the Brahmaputra River. Water Resources Research, 49, 4807-4816. https://doi.org/10.1002/wrcr.20345

Mulligan, M., van Soesbergen, A., \& Sáenz, L. (2020). GOODD, a global dataset of more than 38,000 georeferenced dams. Scientific Data, 7(1), 31. https://doi.org/10.1038/s41597-020-0362-5

Nielsen, K., Stenseng, L., Andersen, O. B., \& Knudsen, P. (2017). The performance and potentials of the CryoSat-2 SAR and SARIn modes for lake level estimation. Watermark, 9, 374. https://doi.org/10.3390/w9060374

Nielsen, K., Stenseng, L., Andersen, O. B., Villadsen, H., \& Knudsen, P. (2015). Validation of CryoSat-2 SAR mode based lake levels. Remote Sensing of Environment, 171, 162-170. https://doi.org/10.1016/j.rse.2015.10.023

Nilsson, C. (2009). Global distribution of reservoirs. Encyclopedia of inland waters, 625-633. https://doi.org/10.1016/B978-012370626$3.00039-9$

Papa, F., Frappart, F., Malbeteau, Y., Shamsudduha, M., Vuruputur, V., Sekhar, M., et al. (2015). Satellite-derived surface and sub-surface water storage in the Ganges-Brahmaputra River Basin. Journal of Hydrology: Regional Studies, 4, 15-35. https://doi.org/10.1016/j. ejrh.2015.03.004

Pekel, J.-F., Cottam, A., Gorelick, N., \& Belward, A. S. (2016). High-resolution mapping of global surface water and its long-term changes. Nature, 540(7633), 418-422. https://doi.org/10.1038/nature20584

Pereira-Cardenal, S. J., Riegels, N. D., Berry, P. A. M., Smith, R. G., Yakovlev, A., Siegfried, T. U., \& Bauer-Gottwein, P. (2011). Real-time remote sensing driven river basin modeling using radar altimetry. Hydrology and Earth System Sciences, 15, 241-254. https://doi.org/ 10.5194/hess-15-241-2011

Richter, B. D., Postel, S., Revenga, C., Scudder, T., Lehner, B., Churchill, A., \& Chow, M. (2010). Lost in development's shadow: The downstream human consequences of dams. Water Alternatives, 3(2), 14-42.

Schneider, C., Flörke, M., De Stefano, L., \& Petersen-Perlman, J. D. (2017). Hydrological threats to riparian wetlands of international importance-A global quantitative and qualitative analysis. Hydrology and Earth System Sciences, 21, 2799-2815. https://doi.org/ 10.5194/hess-21-2799-2017

Schneider, R., Tarpanelli, A., Nielsen, K., Madsen, H., \& Bauer-Gottwein, P. (2018). Evaluation of multi-mode CryoSat-2 altimetry data over the Po River against in situ data and a hydrodynamic model. Advances in Water Resources, 112, 17-26. https://doi.org/10.1016/j. advwatres.2017.11.027

Steunou, N., Desjonquères, J. D., Picot, N., Sengenes, P., Noubel, J., \& Poisson, J. C. (2015). AltiKa altimeter: Instrument description and in flight performance. Marine Geodesy, 38, 22-42. https://doi.org/10.1080/01490419.2014.988835

Sun, S., Yan, X., Cui, P., \& Feng, J. (2011). A four-step method for optimising the normal water level of reservoirs based on a mathematical programming model-a case study for the Songyuan Backwater dam in Jilin province, China. International Journal of Environmental Research and Public Health, 8(4), 1049-1060. https://doi.org/10.3390/ijerph8041049 
Thu, H. N., \& Wehn, U. (2016). Data sharing in international transboundary contexts: The Vietnamese perspective on data sharing in the Lower Mekong Basin. Journal of Hydrology, 536, 351-364. https://doi.org/10.1016/j.jhydrol.2016.02.035

Wang, W., Lu, H., Ruby Leung, L., Li, H. Y., Zhao, J., Tian, F., et al. (2017). Dam construction in Lancang-Mekong River basin could mitigate future flood risk from warming-induced intensified rainfall. Geophysical Research Letters, 44, 10,378-10,386. https://doi.org/ 10.1002/2017GL075037

Wessel, B., Huber, M., Wohlfart, C., Marschalk, U., Kosmann, D., \& Roth, A. (2018). Accuracy assessment of the global TanDEM-X digital elevation model with GPS data. ISPRS Journal of Photogrammetry and Remote Sensing, 139, 171-182. https://doi.org/10.1016/j. isprsjprs.2018.02.017

Zarfl, C., Lumsdon, A. E., Berlekamp, J., Tydecks, L., \& Tockner, K. (2014). A global boom in hydropower dam construction. Aquatic Sciences, 77, 161-170. https://doi.org/10.1007/s00027-014-0377-0

Zhou, T., Nijssen, B., Gao, H., \& Lettenmaier, D. P. (2016). The contribution of reservoirs to global land surface water storage variations Journal of Hydrometeorology, 17, 309-325. https://doi.org/10.1175/JHM-D-15-0002.1 